\title{
Análes Científicos
}

ISSN 2519-7398 (Versión electrónica)

Website: http://revistas.lamolina.edu.pe/index.php/acu/index

\section{Elaboración de un biofertilizante a partir de microorganismos eficientes autóctonos en Perú}

\section{Preparation of a biofertilizer from efficient local microorganisms in Peru}

Juan Alarcon Camacho ${ }^{1 *}$; David Carlos Recharte Pineda²; Franklin Yanqui Díaz²; Sarita Maruja Moreno LLacza3; Isabel Maximiliana Montes Yarasca4; Marilyn Aurora Buendía Molina $^{5}$

\footnotetext{
${ }^{1}$ Escuela Profesional de Agronomía, Facultad de Ingeniería, Universidad Tecnológica de los Andes, Abancay, Apurímac, Perú. Email: jalarconcamacho@yahoo.com

${ }^{2}$ Escuela Profesional de Agronomía, Facultad de Ingeniería, Universidad Tecnológica de los Andes, AbancayApurímac, Perú. drecharte@hotmail.com; franklinnyd@gmail.com

${ }^{3}$ Facultad de Agronomía, Universidad Nacional Agraria La Molina, Lima, Perú. saritamoreno@lamolina.edu.pe

${ }^{4}$ Investigador independiente, Lima, Perú. Email: imontesy@gmail.com

${ }^{5}$ Universidad Nacional Agraria La Molina, Lima, Perú. Email: marilynbuendia@lamolina.edu.pe
}

\section{Resumen}

El objetivo de la investigación fue elaborar un biofertilizante a partir de la recolección de microorganismos eficientes autóctonos (EMA). La colección de los EMA se realizó en el sector Pisonaypata, comunidad San Gabriel, distrito de Abancay, provincia de Abancay, Región Apurimac, Perú. Para ello, se elaboraron ocho capturadores de EMA que fueron colocados a $10 \mathrm{~cm}$ de profundidad del suelo por un periodo de dos semanas. A partir de los EMA capturados en las tarimas, se elaboró cinco litros de biofertilizante, con $25^{*} 10^{6} \mathrm{UFC} / \mathrm{g}$ de aerobios mesófilos viable, 60*10 UFC/mL de Bacillus sp., 20*10 NMP/g de bacterias fijadoras de vida libre y $>34 * 10^{7} \mathrm{UFC} / \mathrm{g}$ de Lactobacillus sp. En conclusión, utilizar EMA en la elaboración de biofertilizantes, permite mayor efectividad en el campo, por estar los EMA adaptados a las condiciones del suelo de cada región. La recomendación del uso de biofertilizantes, debe hacerse inicialmente como un complemento a la fertilización sintética, con la finalidad de sustituirla a mediano o largo plazo de acuerdo a las condiciones de suelo, manejo y respuesta del cultivo.

Palabras clave: Fertilización en Drench; microorganismos eficientes; biofertilizante; cepas nativas; agricultura.

Forma de citar el artículo: Alarcon et al., 2019. Elaboración de un biofertilizante a partir de microorganismos eficientes autóctonos en Perú. Anales Científicos 80 (2): 515-522 (2019).

DOI: http://dx.doi.org/10.21704/ac.v80i2.1484

Autor de correspondencia (*): Juan Alarcon Camacho. Email: jalarconcamacho@yahoo.com (c) Universidad Nacional Agraria La Molina, Lima, Perú. 


\begin{abstract}
The objective of the research was to elaborate a biofertilizer from the collection of autochthonous efficient microorganisms (EMA). The EMA collection was made in the Pisonaypata sector, San Gabriel community, Abancay district, Abancay province, Apurímac region, Peru. For this, eight EMA grabbers were made and placed at a depth of $10 \mathrm{~cm}$ from the ground for a period of two weeks. From the EMAs that were captured in the pallets, five liters of biofertilizer were prepared, with $25^{*} 10^{6} \mathrm{UFC} / \mathrm{g}$ of viable mesophilic aerobes, $60 * 10 \mathrm{UFC} / \mathrm{mL}$ of Bacillus sp., $20 * 10 \mathrm{NMP} / \mathrm{g}$ of bacteria Free-life fixatives and $>34 * 10^{7}$ UFC/g of Lactobacillus sp. In conclusion, using EMA in the preparation of biofertilizers, allows greater effectiveness in the field, since the EMAs are adapted to the soil conditions of each region. The recommendation of the use of biofertilizers should be made initially as a complement to the synthetic fertilization, with the purpose of replacing it in the medium or long term according to the soil conditions, management and response of the crop.
\end{abstract}

Keywords: Fertilization in Drench; efficient microorganisms; biofertilizer; native strains; agriculture.

\section{Introducción}

Los biofertilizantes contienen microorganismos, que aplicados al suelo y/o planta restaura la fertilidad y la microbiota benéfica de los agroecosistemas dañados por la contaminación de agroquímicos (Armenta-Bojórquez et al., 2010; Armenta et al., 2010). Los microorganismos que se encuentran en los biofertilizantes se clasifican en dos grupos: El primer grupo, son microorganismos con capacidad de sintetizar substancias que promueven el crecimiento de la planta, fijando nitrógeno atmosférico (Castillo et al., 2016), solubilizando hierro y fósforo inorgánico, mejorando la tolerancia al estrés por sequía, salinidad, metales tóxicos y exceso de pesticidas, por parte de la planta. Los géneros más estudiados de las bacterias fijadoras de nitrógeno de vida libre son Azospirillum, Azotobacter, Beijerinckia y Klebsiella, siendo los cultivos de caña de azúcar, arroz, sorgo, trigo y pastos tropicales forrajeros donde más se ha estudiado el proceso de fijación de nitrógeno por bacterias asociativas y de vida libre (Döbereiner et al., 1995), las mayores cantidades de nitrógeno atmosférico es fijado por las leguminosas en asociación simbiótica con bacterias del género Rhizobium (Richards, 1987). Los microorganismos que proporcionan fósforo a las plantas, entre los más importantes se encuentran los hongos micorrízicos que, en asociación simbiótica con las plantas, incrementan la captación de nutrimentos minerales del suelo principalmente fósforo (Alloush et al., 2000).

El segundo grupo, son microorganismos capaces de disminuir o prevenir los efectos de los microorganismos patógenos (Lucy et al., 2004). Aunque hay microorganismos que se encuentran dentro de los dos grupos, promueven el crecimiento de la planta e inhiben los efectos de los microorganismos patógenos (Kloepper et al., 1980). Por ejemplo, el Bacillus subtilis que produce auxinas que promueven el crecimiento de tomate e inducen resistencia sistémica contra Fusarium oxysporum, que provoca marchitez y pudrición de las raíces (Gupta et al., 2000).

El desarrollo sostenible, se logra utilizando biofertilizantes, recomendación de la III Cumbre de la Tierra, celebrada en Río de Janeiro en 1992 (Sequeiros, 1998); el desarrollo de la biotecnología ha hecho posible obtener bioabonos de mayor 
calidad en comparación con los bioles, que son preparados con microorganismos eficientes (EM) (Suárez, 2009). Los EM son cultivos microbianos benéficos presentes en ecosistemas naturales (Higa \& Parr, 2013) que en contacto con la materia orgánica secretan sustancias benéficas e inhiben de manera controlada patógenos no deseados (Cóndor et al., 2007). Entre los principales tipos de EM se encuentran bacterias fotosintéticas, bacterias ácido lácticas (BAL), levaduras y actinomicetos, de amplia difusión y con múltiples aplicaciones biotecnológicas en más de 180 países (Higa \& Parr, 2013).

En el contexto actual, la inseguridad alimentaria y el cambio climático afecta las zonas altoandinas, que son pobres y sus ecosistemas son frágiles (FAO, 2005), los abonos líquidos permiten incrementar la productividad y calidad de los pastos, forrajes y cultivos agrícolas que alimentan al ganado, pobladores y en gran medida a la población nacional (Ticona et al., 2016).

El objetivo del presente estudio fue evaluar los Microorganimos Eficientes Autoctonos presentes en el biofertilizante, a fin de determinar su uso en campo. Al ser un estudio pionero orientado a los agroecosistemas altoandinos, el resultado obtenido establece las bases para realizar más estudios mediante innovación biotecnológica que trae beneficios económicos y ambientales.

\section{Materiales y métodos}

La captura de EMA se realizó en el bosque, donde no hubo actividad agrícola, localizado en el sector Pisonaypata, comunidad San Gabriel, distrito de Abancay, provincia de Abancay, Región Apurímac, Perú; con localización geográfica de $72^{\circ} 24^{\prime} 01^{\prime}$ " longitud Oeste y $13^{\circ} 22^{\prime}$ '22" latitud Sur, a una altura de 1832 m.s.n.m. El clima es cálido a templado, con noches frescas (Recharte, 2015), La temperatura media es de $18^{\circ} \mathrm{C}$, la precipitación media anual es de $500-600 \mathrm{~mm}$ y la humedad relativa es de $45-55 \%$.

Se elaboró ocho capturadores de microorganismos eficientes nativos, siguiendo el procedimiento de Suquilanda (2006). Para capturar los microorganismos, se enterró las tarimas a $10 \mathrm{~cm}$ de profundidad en el suelo; cada tarima estuvo conformada por un pote tapado con tela nylon, en su interior se colocó $250 \mathrm{~g}$ de arroz cocinado sin sal, dos cucharadas de melaza y dos cucharadas de harina de pescado. Sobre la tela de nylon, se colocó materia orgánica, recogida de los sectores circundantes, en proceso de descomposición. A los 14 días se desenterró la tarima, obteniéndose arroz impregnado de microorganismos del lugar (Figura 1).

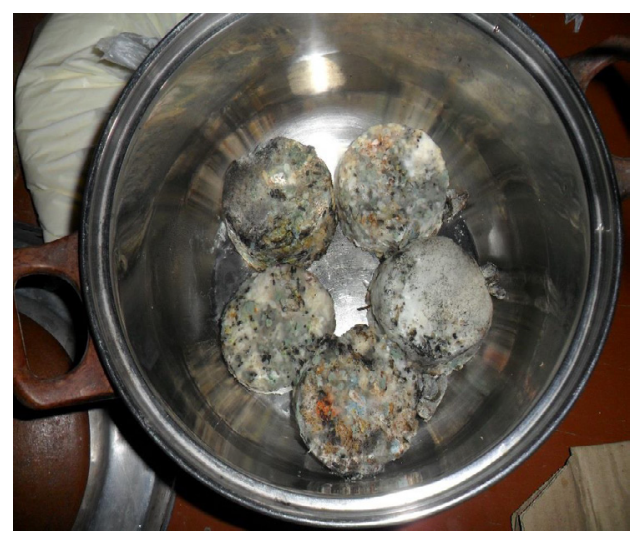

Figura 1. Arroz con microorganismos capturados

Para la elaboración de cinco litros de solución madre de EMA, se colocó en un recipiente de plástico el arroz impregnado de EMA, se agregó al recipiente dos litros de agua hervida fría, dos litros de melaza y un litro de yogur; se mezcló y licuó todo el contenido por cinco minutos; luego se filtró la mezcla, obteniendo la solución madre (Figura 2). 


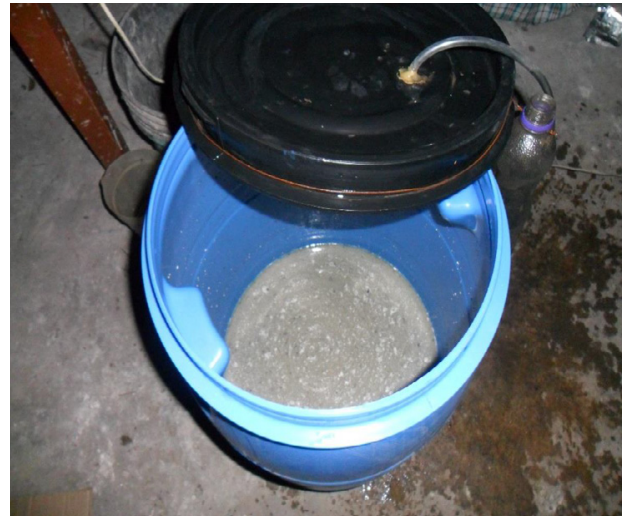

Figura 2. Solución madre de EMA

El biofertilizante, se obtuvo al agregar en el cilindro de plástico la solución madre, tres litros de yogur, tres litros de melaza, cuatro litros de caldo de pescado y 20 litros agua hervida fría. Se cerró herméticamente el tanque, por un periodo de 18 días, para evitar la entrada de oxígeno y con ello activar los hongos, bacterias benéficas y levaduras (Rodríguez \& Torres, 2014), la mezcla se almacenó bajo condiciones de fermentación anaeróbica.

La población microbiana de la solución madre se determinó de una muestra de 500 $\mathrm{ml}$, en el Laboratorio de Ecología Microbiana y Biotecnología "Marino Tabusso" de la Universidad Nacional Agraria La Molina con el método del Número más Probable (NMP) establecido por la ICMSF (1983); utilizando el medio de cultivo recomendado por Zapater (1975).

\section{Resultados y discusión}

En la Tabla 1 se presentan las poblaciones microbiológicas de la solución madre. Los valores $<3,<10$ y $<100$ indican ausencia de microorganismos en ensayo. La presencia de Bacillus sp. tiene un efecto positivo en el desarrollo vegetal y en el aumento del potencial productivo por la capacidad de estos microorganismos para producir compuestos orgánicos, fijar nitrógeno (Seldin et al., 1984) y solubilizar fosfatos (Patiño, 2010), son acciones que efectúan mediante enzimas como nitrogenasas y fitasas (Corrales et al., 2017). Haefner et al. (2005) reportó que la $B$. subtilis permite la reducción del ácido fítico impidiendo que se presente quelación de los minerales que se encuentran en la biomasa, evita que el fósforo y las diferentes trazas de elementos se vuelvan insolubles y se precipiten. Portela et al. (2013) reportó que las bacterias solubilizadoras de fósforo más eficientes, son de los géneros Bacillus, Pseudomonas, Rhizobium, Burkholderia, Achromobacter, Agrobacterium, Microccocus, Aerobacter, Azotobacter y Erwinia, y hongos saprófitos, como Aspergillus niger, Penicillium bilaii, Penicillium simplicissimun, Trichoderma harzianum, y Cladosporium herbarum. En ello radica la importancia de la acción de estas bacterias frente al ciclo del fósforo y su función de beneficio a la biodiversidad de la flora y los suelos.

Tabla 1. Análisis microbiológico de la solución madre

\begin{tabular}{ll}
\hline \multicolumn{1}{c}{ Análisis microbiológico } & \multicolumn{1}{c}{ cantidad } \\
\hline Recuento de aerobios mesófilos viable (UFC/g) & $25^{*} 10^{6}$ \\
Recuento de mohos y levaduras (UFC/g) & $<10$ \\
Recuento de Bacillus $s p$. (UFC/mL) & $60 * 10$ \\
Recuento de actinomicetos (UFC/g) & $<100$ \\
Enumeración de Pseuomonas sp. (NMP/g) & $<3$ \\
Enumeración de bacterias fijadoras de vida libre (NMP/g) & $20 * 10$ \\
Recuento de Lactobacillus sp. & $>34 * 10^{7}$ \\
\hline
\end{tabular}


La fijación del nitrógeno a través del Bacillus mejora la fertilidad del suelo en comparación con la fertilización orgánica y química que genera altos niveles de contaminación con sales nitrogenadas, metales pesados y microorganismos patógenos para el ser humano y los animales. Especies como B. fusiformis aislados de maíz, trigo y arroz, han sido caracterizados con una elevada actividad nitrogenasa, por su excelente fijación de nitrógeno $\mathrm{y}$, la especie $B$. firmus tiene la capacidad de potenciar la actividad nitrogenasa de microorganismos aislados en plantas como Dactylus glomerata, aumentando la cantidad de nitrógeno fijado por la planta, lo cual conlleva a una reducción considerable en el uso de fertilizantes nitrogenados de origen químico (Zlotnikov et al., 2001).

Las bacteris del género Bacillus tienen la capacidad para formar esporas que permanecen metabólicamente inactivas pero viables en condiciones adversas, son apropiados para la formulación de productos estables que benefician los cultivos agrícolas a través de mecanismos indirectos (Portela et al., 2013). Terry et al. (2005) reportaron que la presencia de Bacillus sp. es de gran importancia porque forma parte de la comunidad microbiana de la rizosfera del tomate $\left(1,5 * 10^{6}\right)$. Mientras que, Orhan et al. (2006) al evaluar dos cepas de Bacillus en un cultivo ecológico de frambuesa en Turquía, evidenció el efecto positivo en el crecimiento vegetal. También, presenta resistencia sistémica inducida frente a bacterias, hongos patógenos, virus sistémicos y nematodos de la raíz (Kloepper et al., 2004). Como biofertilizante es una opción amigable para el suelo y el ambiente que da respuesta a la necesidad de implementar la agricultura sostenible (Corrales et al., 2017).

Las bacterias mediadoras de vida libre que participan mediante sus procesos metabólicos en la fijación de nitrógeno (Mishustin et al., 1971) y solubilización de fostato son:
Bacillus spp., Clostridium spp., Klebsiella spp., Pseudomonas spp., Enterobacter spp., Azotobacter spp., y Azospirillum spp., las que han sido aísladas de la rizosfera, donde el número de microorganismos diazótrofos es generalmente mayor por la liberación y concentración disponible de nutrientes en forma de compuestos orgánicos (Terry et al., 2005). A nivel mundial, se está investigando las bondades de utilizar bacterias asimbioticas del género Azotobacter y Azospirillum en la reducción del periodo de germinación de las semillas de tomate, ají y algodón (Recharte, 2015). Inocular con estos microorganismos, incrementa la producción de hormonas del crecimiento e incrementan la respuesta a la fertilización química u orgánica.

Las Bacterias ácido lácticas (Lactobacillus spp.) producen ácido láctico como principal producto de la transformación de hidratos de carbono (Buchelli, 2014) y otros carbohidratos, producidos por las bacterias fototrópicas y levaduras. Desde tiempos antiguos el yogur y encurtidos son hechos con bacterias ácido lácticas. Así mismo esta fermentación produce sustancias antimicrobianas, incluyendo a las bacteriocinas que tienen la capacidad de inhibir las bacterias patógenas, el deterioro de los alimentos (Mata, 1999) y ayuda a la descomposición de materiales como la lignina y la celulosa fermentándolos, removiendo efectos no deseables de la materia orgánica no descompuesta (Rodríguez, 2009). Las bacterias ácido lácticas tienen la habilidad de suprimir enfermedades incluyendo microorganismos como fusarium (EM, 2012), que aparecen en programas de cultivos continuos. Los usos de bacterias ácido lácticas reducen las poblaciones de nematodos, controla la propagación y dispersión de fusarium, y gracias a ello induce un mejor ambiente para el crecimiento de los cultivos (Chamikag, 2017).

\section{Conclusiones}


La utilización de cepas nativas de microorganismos en la elaboración de biofertilizantes, presentan mayores posibilidades de efectividad en el campo, por estar adaptados a las condiciones del suelo de cada región. La recomendación del uso de biofertilizantes, debe hacerse inicialmente como un complemento a la fertilización sintética, con visión de sustituirla a mediano o largo plazo de acuerdo a las condiciones de suelo, manejo y respuesta del cultivo.

\section{Literatura citada}

Alloush, G.A.; Zeto, S.K., Clark, N. 2000. Phosphorus source, organic matter, and arbuscular mycorrhizal effects on growth and mineral acquisition of chickpea grown in acidic soil. Journal of Plant Nutrition 23(9):1351-1369.

Armenta, B.A.D.;García, G.C.; Camacho, B.J.R.; Apodaca, S.M.A.; Montoya, L.G.; Nava, P.E. 2010. Biofertilizantes en el desarrollo agrícola de México. Ra-Ximhai, 6: 51-56.

Armenta-Bojórquez, A.D.; GarcíaGutiérrez, C.; Camacho-Báez, J.R.; Apodaca-Sánchez, M.A.; GerardoMontoya, L.; Ava-Pérez, E. 2010. Biofertilizantes en el desarrollo agrícola de México. Revista Ra Ximhai 6 (1): 51- 56.

Buchelli, H. 2014. Producción de biofertilizante de bagazo de cebada, excretas de vacuno y suero de quesería mediante fermentación homoláctica. Tesis para optar el título de ingeniero ambiental, Universidad Nacional Agraria La Molina, Lima, Perú. 97pp.

Castilllo, C.; Huenchuleo, M.; Michaud, A.; Solano, J. 2016. Micorrización en un cultivo de papa adicionado del biofertilizante Twin-N establecido en un Andisol de la Región de La
Araucanía. IDESIA 34(1): 39-45.

Chamikag, H. 2017. Dosis de microorganismos eficaces (EM1) con abonamiento uniforme de vacaza y su efecto sobre las características agronómicas del pasto Panicum máximum cv, Tanzania en Zungarococha, Perú - 2016. Tesis de Ingeniero Agrónomo. Universidad Nacional de la Amazonia Peruana, Iquitos, Perú. 87pp.

Cóndor, A.F.; Gonzáles, P. \& Lokare, C. 2007. Effective Microorganisms: Myth or reality? Revista Peruana de Biología 14 (2): 315-319.

Corrales, L.; Caycedo, L.; Gómez, L.; Ramos, S.; Rodríguez, J. 2017. Bacillus spp: una alternativa para la promoción vegetal por dos caminos enzimáticos. NOVA. 15(27): 45-65.

Döbereiner, J.; Urquiaga, S.; Boddey, R.M.; Ahmad, N. 1995. Alternatives for nitrogen of crops in tropical agriculture. Nitrogen Economy in tropical Soil. Fertilizar Research. 42:339-346.

EM [Ecologic Maintenances]. 2012. Microorganismos efectivos EM en la Agricultura. Yucatán, México. Disponible en http://www. emmexico.com

FAO [Organización de las Naciones Unidas para laAgricultura y laAlimentación]. 2005. Situación actual de los Camélidos Sudamericanos en Perú. Proyecto de cooperación técnica en apoyo a la crianza y aprovechamiento de los Camélidos Sudamericanos en la Región Andina (TCP/RLA/2914). Santiago de Chile. 63 p.

Gupta, V.P.; Bochow, H.; Dolej, S.; Fischer, I. 2000. Plant growth-promoting Bacillus subtilis strain as potential inducer of systemic resistance 
in tomato against Fusarium wilt. Zeitschrift fur Pflanzenkrankneiten und Pflanzenschutz 107 (2):145-154.

Haefner, S.; Knietsch, A.; Scholten, E.; Braun, J.; Lohscheidt, M.; Zelder, O. 2005. Biotechnological production and applications of phytases. Appl Microbiol Biotechnol 68: 588-597.

Higa, T. \& Parr, J.F. 2013. Microorganismos benéficos y efectivos para una agricultura y medio ambiente sostenibles. Beltsville, Maryland, Estados Unidos: Centro Internacional de Investigación de Agricultura Natural y Departamento de Agricultura de los Estados Unidos. $13 \mathrm{p}$.

ICMSF [International Commission on Microbiological Specifications for Foods]. 1983. 2nd ed. Vol. 1 Part 2, (Trad. 1988). Reimp. 2000. Editorial Acribia.

Kloepper, JW.; Ryu, CM.; Zhang, S. 2004. Induced systemic resistance and promotion of plant growth by Bacillus spp. Phytopathology 94: 1259-1266.

Kloepper, J.W.; Schroth, M.N.; Miller, T.D. 1980. Effects of Rhizosphere colonization by plant growthpromoting rhizobacteria on potato plant development and yield. Phytopathology 70:1078-1082.

Lucy, M.; Reed, E.; Glick, B.R. 2004. Applications of free living plant growth-promoting rhizobacteria. Antonie Van Leeuwenhocka 86: 1-25.

MATA C. 1999. Empleos de fermentos lácticos en la fabricación de productos cárnicos. Tesis doctoral. Universidad de Córdova. Colombia. 20-25p.

Mishustin, EN.; Shilnikova, VK, 1971.
Fijación biológica del nitrógeno de la atmósfera, Macmillan, Londres

Orhan, E.; Esitken, A.; Ercisli. S.; Turan, M.; Sahin, F. 2006. Effects of plant growth promoting rhizobacteria (PGPR) on yield, growth and nutrient contents in organically growing raspberry. Sci. Hort. 111: 38-43.

Patiño, C. 2010. Solubilización de fosfatos por poblaciones bacterianas aisladas de un suelo del Valle del Cauca: estudio de biodiversidad y eficiencia. [Trabajo de Grado], Universidad Nacional de Colombia. Palmira. Colombia.

Portela, D.; Chaparro, A.; López, S. 2013. La biotecnología de Bacillus thuringiensis en la agricultura NOVA. 2013; 11: 87-96.

Recharte, D. 2015. Evaluación de microorganismos eficientes autóctonos en el rendimiento del cultivo de tomate (Lycopersicum esculentum, Mill) en San Gabriel, Abancay. Tesis de Ingeniero, Universidad Tecnológica de los Andes, Abancay. Perú. 94pp.

Richards, B. N. 1987. The microbiology of terrestrial ecosystems. LST; John Wiley and Sons. Inc. New York. 327329 pp.

Rodríguez, J. 2009. Mitigación y biorremediación de suelos contaminados por el derrame de combustible diésel 2 en la Quebrada del Toro, Camaná. Ciencia y Desarrollo 10 (3): 37-51.

Rodríguez, N.\& Torres, Z. 2014. Producción de Microorganismos de Montaña para el Desarrollo de una Agricultura Orgánica. Dirección General de Investigación. Universidad Peruana Union, Disponible en: https://estaticos.qdq.com/swdata/ 
files/950/950904418/CIn_3256.pdf

Seldin, J.D.; Van Elsas, E.G.; Penido, C. 1984. Bacillus azotofixans. nov. a Nitrogen-Fixing Species from Brazilian Soils and Grass Roots. International Journal of Systematic Bacteriology 4 (34): 451-456.

Sequeiros, L. 1998. De la III Cumbre de la Tierra (Río de Janeiro, 1992) al fracaso de la Conferencia de Kioto (1997): Claves para comprender mejor los problemas ambientales del Planeta. Enseñanzas de las Ciencias de la Tierra 6 (1): 3-12.

Suárez, D.M. 2009. Caracterización de un compuesto orgánico producido en forma artesanal por pequeños agricultores en el Dpto. de Magdalena. Tesis de Maestría en Ciencias Agrarias con Énfasis en Suelos. Santa Marta, Colombia. 93 p.

Suquilanda, M. 2006. Fertilización Orgánica. Manual Técnico. Ediciones UPSFUNDAGRO. Quito, Ecuador. p. 23-25.

Terry, E.; Leyva, A.; Hernàndez A. 2005. Beneficios de los Microorganismos como biofertilizantes eficientes para el cultivo de tomate (Lycopersicon esculentum, Mill). Revista Colombiana de Biotecnología 7 (7): 47-54.

Ticona, O.; Céspedes, R.; Martínez, Z. \& Chipana, G. 2016. Aplicación de Biol y riego por aspersión en la producción de cebada forrajera (Hordeum vulgare) en el municipio de Viacha. Revista de Investigación e Innovación Agropecuaria y de Recursos Naturales 3 (3): 39-47.

Zapater, J.M. 1975. Evaluación en el maíz del coeficiente rizósfera-suelo $(\mathrm{R} / \mathrm{S})$, referidos a bacterias libres fijadoras de N. Anales Científicos UNA 13:4557.

Zlotnikov, A.; Shapovalov, Y.; Makarov, A. 2001. Association of Bacillus firmus E3 and Klebsiella terrigena E6 with increased ability for nitrogen fixation. Soil Biology and Biochemistry 33 (11): 1525-1530. 